EGU2020-9284

https://doi.org/10.5194/egusphere-egu2020-9284

EGU General Assembly 2020

(c) Author(s) 2020. This work is distributed under

the Creative Commons Attribution 4.0 License.

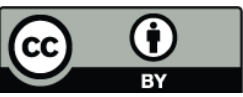

\title{
What explains the elevational upward shifts at the treeline ecotone?
}

\author{
Àngela Manrique-Alba and Santiago Beguería \\ Consejo Superior Investigaciones Científicas, Estación Experimental Aula Dei, Zaragoza, Spain (amanrique@eead.csic.es)
}

Temperatures have increased worldwide in the last decades, with the most pronounced and rapid changes occurring at high altitudes and latitudes. Climate change has played an important role in modifying the altitudinal location of the treeline ecotone, i.e. the transition from timber line (the upper forest limit, defined by the presence of a continuous forest cover) to the treeline (the last upright trees reaching 2 or $3 \mathrm{~m}$ in height). Moreover, the influence of recent land use change (e.g., changes in pastoral use, tourism development) in treeline dynamics is increasingly acknowledged. We have compiled a dataset of treeline changes over the Pyrenees mountain range, extending over more than 12000 linear kilometres, representing a large study area that extends across a broad range of environmental conditions. The main objective was to assess the effects of climate change, past land uses and physiography on the treeline dynamics between 1956 and 2015. To explore the variation in treeline shifts we used pairs of aerial photographs taken in 1956 and 2015 and we identified the position of the tree line using a criterion based on canopy cover thresholds. Our findings show significant differences between tree line dynamics for the two analysed periods and allow us to infer the relative importance of climatic factors, land use change, and local anthropogenic influence modulating the treeline structure and its dynamics. 